\title{
Heritable Pulmonary Arterial Hypertension
}

National Cancer Institute

\section{Source}

National Cancer Institute. Heritable Pulmonary Arterial Hypertension. NCI Thesaurus.

Code C121945.

A rare, progressive, autosomal dominant inherited disorder. It is caused by mutation in the BMPR2 gene in most cases. It is characterized by abnormally high blood pressure in the pulmonary artery, caused by obstruction and obliteration of the small pulmonary arteries. 